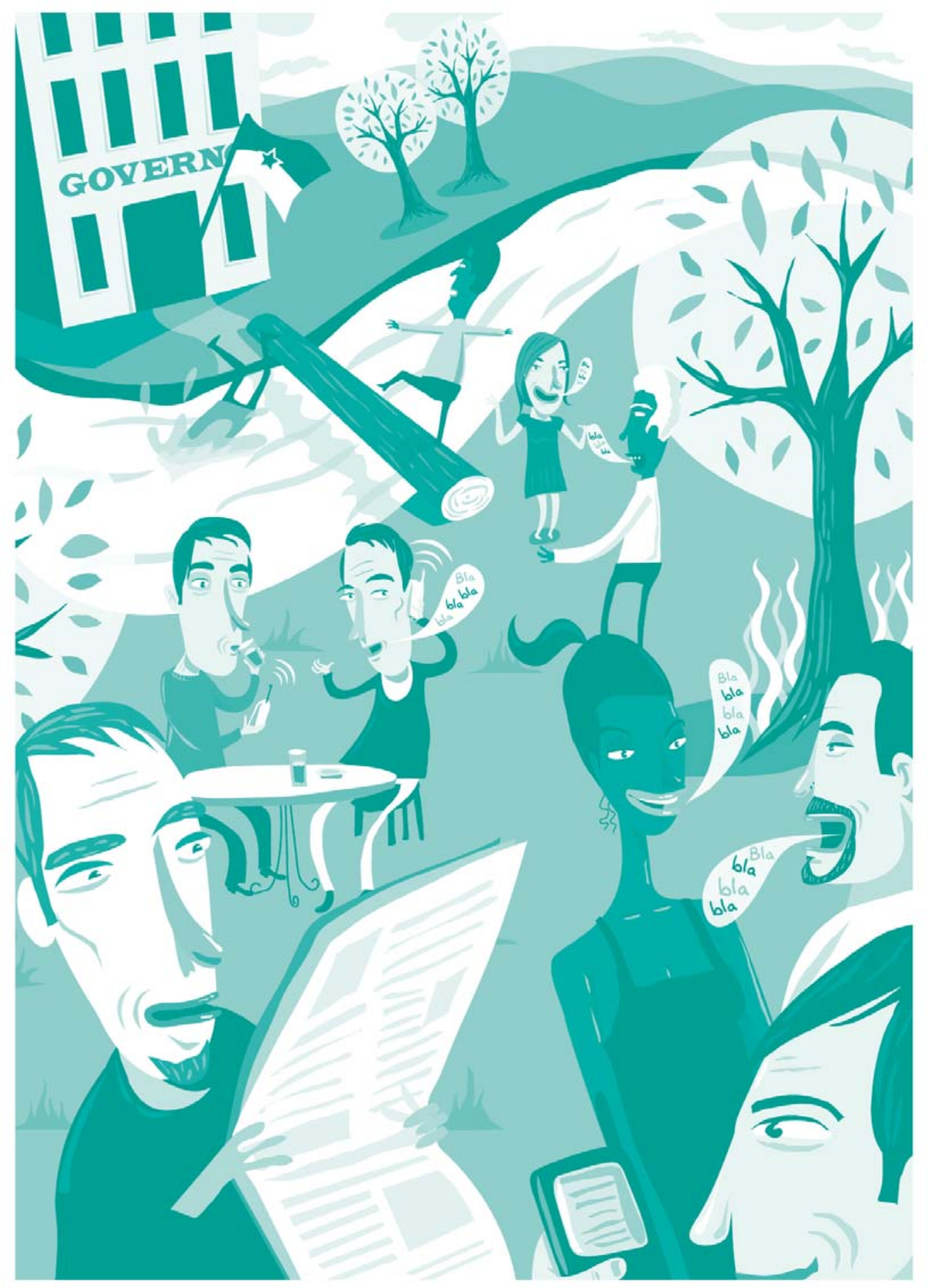




\section{Gobernabilidad Mediática Mass media y grado de gobierno: difícil (des)encuentro}

José Luis Exeni

- Doctor en Ciencia Política y Maestro en Ciencias Sociales por la Facultad Latinoamericana de Ciencias Sociales (Flacso), México

- Especialista en políticas de comunicación y planificación de la comunicación para el desarrollo en democracia

- Comunicador e investigador boliviano, actualmente es investigador del Informe sobre Desarrollo Humano del PNUD en Bolivia

- jose.exeni@undp.org 


\section{Resumo}

O presente artigo busca explorar a difícil relação entre midiatização e governabilidade de uma perspectiva conceitual, mais do que histórica ou empírica. O propósito é discutir algumas chaves de leitura, ou seja, propor um diálogo sobre o tema. Para tanto, a exposição é organizada em torno da idéia de governabilidade midiática. O propósito analítico é avançar na compreensão do modo pelo qual os meios de comunicação de massa, no cenário da Comunicação Política, incidem sobre a democracia e, mais ainda, interagem com a (in)governabilidade do regime político.

PALAVRAS-CHAVE: MÍDIA • MIDIATIZAÇÃO • GOVERNABILIDADE • GOVERNABILIDADE MIDIÁTICA - MASS MEDIA - COMUNICAÇÃO PÚBLICA

\section{Abstract}

This article seeks to explore the difficult relation between mediatization and governability from a conceptual perspective, rather than a historical or empirical one. The purpose is to discuss some keys to reading, i.e. to propose a dialog on the theme. To that end, the exposition is organized around the idea of mediatic governability. The analytical purpose is to further the understanding of how the means of mass communication affect democracy in the Political Communication scenario and, more importantly, how they interact with the (un)governance of the political regime.

KEYWORDS: MEDIA • MEDIATIZATION - GOVERNANCE • MEDIATIC GOVERNANCE • MASS MEDIA - PUBLIC COMMUNICATION

\section{Resumen}

El presente artículo busca explorar la difícil relación entre mediatización y gobernabilidad desde una perspectiva más bien conceptual que histórica o empírica. El propósito es discutir algunas claves de lectura o, mejor, proponer un diálogo sobre el tema. Para el efecto, la exposición es organizada en torno a la idea de gobernabilidad mediática. El reto analítico es avanzar en la comprensión del modo en que los medios de comunicación masiva, en el escenario de la Comunicación Política, inciden sobre la democracia y, más todavía, interactúan con la (in)gobernabilidad del régimen político.

PALABRAS CLAVES: MEDIA - MEDIATIZACIÓN • GOBERNABILIDAD - GOBERNABILIDAD MEDIÁTICA - MASS MEDIA - COMUNICACIÓN PÚBLICA 
Los medios, iesa amenaza!

S hubiese que rastrear la partida de nacimiento del nexo entre la acción de los medios y lo gobernable del régimen político, bien podríamos remontarnos al informe de la Comisión Trilateral sobre "La gobernabilidad de la democracia"1. En aquel polémico documento ${ }^{2}$ se identifican siete áreas de crítica debilidad y de ruptura potencial, una de las cuales plantea la "restauración del balance entre el gobierno y los medios de comunicación". El supuesto es que hay un creciente desequilibrio entre la distribución del poder y la distribución de la responsabilidad, y que el balance se ha inclinado demasiado en contra de los gobiernos. El remedio: quienes han adquirido nuevo poder (como los medios de comunicación, sindicatos, intelectuales y tecnócratas), deben usarlo en forma responsable. En el caso de los mass media, el texto no admite dudas: "la prensa se ha hecho más poderosa y menos responsable, (por lo que) se requieren importantes medidas para restaurar un balance apropiado entre la prensa, el gobierno y las otras instituciones de la sociedad" (Comisión Trilateral, 1977, p. 391-393).

¿Cuáles son esas importantes medidas que - según tal reporte - permitirán restablecer, para bien y beneficio de la gobernabilidad, el equilibrio perdido? Si bien los autores son cuidadosos al remarcar que "la libertad de prensa es esencial para el efectivo funcionamiento del gobierno democrático", no dudan en advertir que tal libertad puede ser objeto de abuso; esto es, de un mal empleo por parte de quienes están directamente vinculados con ella. En ese horizonte proponen un doble camino para enfrentar los potenciales excesos de la libertad de prensa y, de ese modo, equilibrar la relación entre gobierno y complejo mediático: a) asegurar la existencia de una "prensa libre y responsable" mediante mecanismos de queja y sanción creados por los propios medios; y b) proteger los intereses y derechos del gobierno y de la sociedad a través de instrumentos de regulación externos a los medios.

El supuesto básico del discurso trilateral es que los medios y sus operadores, con mucho poder y poca responsabilidad, pueden provocar efectos dañinos en la fun-

1 El papel de los medios masivos y su relación con el sistema político, el gobierno, el poder y la democracia fueron estudiados ampliamente antes del reporte trilateral; empero, éste inauguró un vínculo particular entre la comunicación mediatizada y lo gobernable al introducir en el debate académico y político una problemática con denominación específica: la gobernabilidad.

2 El reporte Trilateral fue publicado el año 1975. Su redacción se encargó a tres prestigiosos intelectuales: el francés Michel Crozier, el estadounidense Samuel P. Huntington y el japonés Joji Watanuki. 
ción de gobierno; es decir, no solamente ejercen influencia sobre el poder político, sino que son un (contra)poder. Así parece predominar una visión de los medios como amenaza. El riesgo es que, con la balanza desequilibrada a su favor, los medios de comunicación subordinen al sistema político y provoquen irremediables trastornos en el régimen democrático. En el origen de la relación gobernabilidad/mediatización, pues, los mass media son concebidos como potencial fuente de inestabilidad y desorden ${ }^{3}$.

\section{Lo "mediático" como adjetivo}

¿Qué implicación tiene añadir el adjetivo mediática al sustantivo gobernabilidad? De modo más específico: ¿cuál es la diferencia sustancial entre la gobernabilidad a secas y la gobernabilidad mediática? En principio, el adjetivo mediática hace referencia a una gobernabilidad, por una parte, sujeta a los efectos de los mass media; y, por otra, inmersa con mayor o menor intensidad en las lógicas y mecanismos de la comunicación política. En clave de problemas, la gobernabilidad mediática se concibe como:

i. El modo en que el complejo mediático en general y cada uno de sus medios masivos en particular influyen en la condición y, particularmente, en la sensación de in/ gobernabilidad, ya sea en función de alerta temprana de conflictos o como detonantes de situaciones de inestabilidad y crisis.

ii. Los efectos que provoca la comunicación política, específicamente el proceso de construcción de agenda mediática, en: a) la expresión de demandas sociales y desafíos políticos por parte de la sociedad, b) la (des)activación de los mecanismos de atención y decisión del sistema político y c) la intermediación (relación, representación) entre ambos.

iii. La incidencia de la comunicación política, en especial de la mediatización (en el marco del gobierno representativo), sobre las dimensiones de legitimidad y de eficacia de la gobernabilidad.

iv. La manera en que los mass media, concebidos como instrumento y escenario de la política, pero fundamentalmente como actores estratégicos, intervienen en el fomento-control de la gobernabilidad así como en la detonación-agravamiento de la ingobernabilidad; y la forma en que esta acción contribuye o interfiere en la consolidación del régimen democrático.

Como se habrá notado, la noción de gobernabilidad mediática que aquí proponemos es todavía demasiado amplia. En lo que sigue intentaremos avanzar en su delimitación.

3 Huntington (1990) ya había perfilado esa posición al ubicar a los medios de comunicación (en su función de crear necesidades y excitar aspiraciones y expectativas) como fuente de una cadena nociva que conducía a la inestabilidad política. 


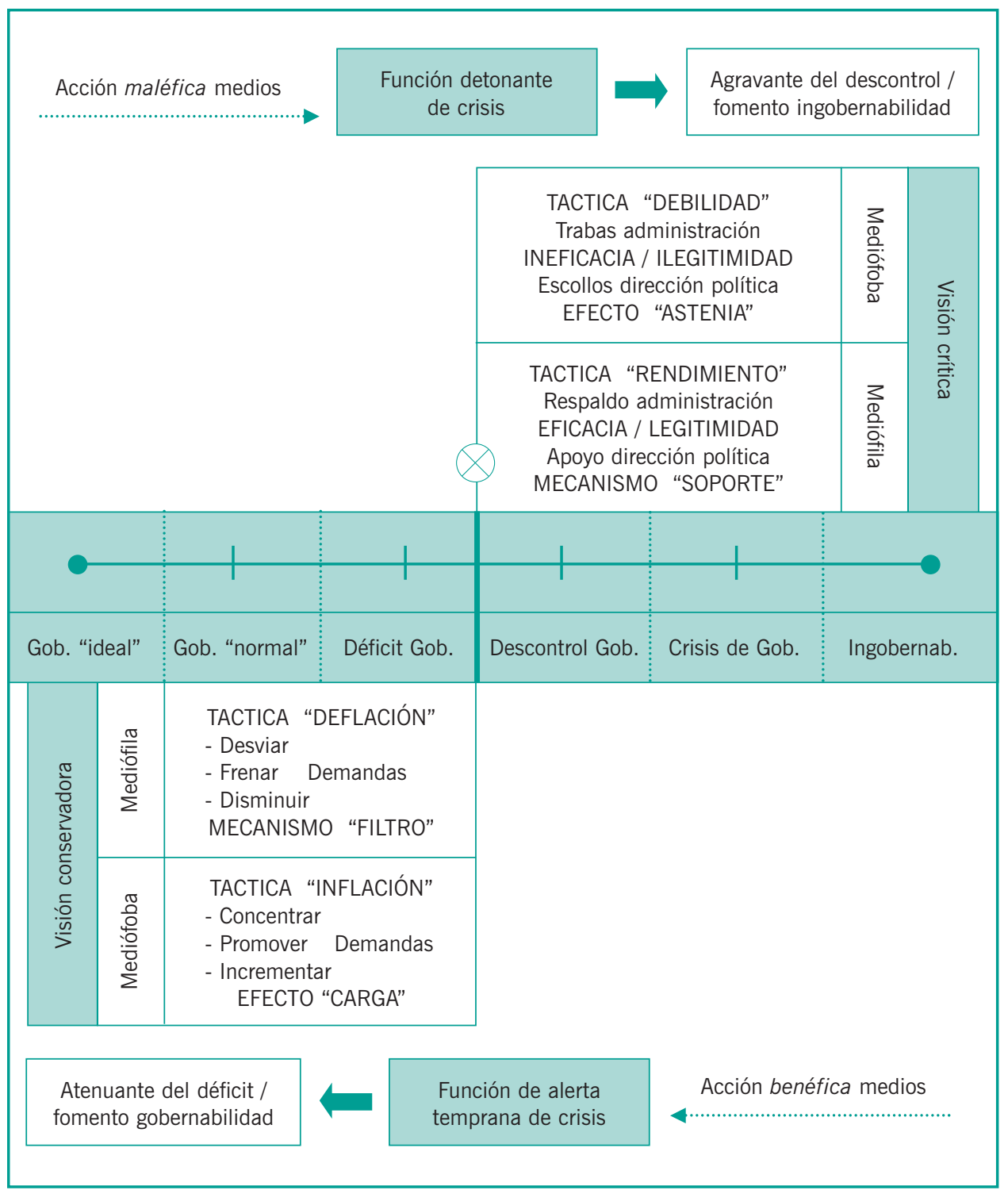

\section{Influencia de doble ruta}

En el propósito de ubicar la acción de los mass media en un escenario de situaciones políticas de in/gobernabilidad, propongo un gráfico como guía de exposición.

Una observación del gráfico nos brindará algunas claves de lectura, necesariamente 
esquemáticas, para abordar el tema de esta reflexión. De inicio podemos sostener, ubicándonos como observadores en la frontera entre el déficit de gobernabilidad y su descontrol (círculo blanco), que los medios influyen en dos sentidos:

a) Hacia la izquierda del continuo, la acción mediática puede incidir en el manejo del desequilibrio que configura un escenario de déficit de gobernabilidad, contribuyendo a evitar el paso a una situación política de descontrol y apuntalando, más bien, el tránsito hacia un estado de normalidad en el ejercicio de la función/responsabilidad de gobierno con un nivel de conflictos tolerable e institucionalmente controlado por el sistema. Aquí puede hablarse de una función de alerta temprana, en sentido de que los medios ofrecerían a los actores del ejecutivo/aparato estatal un mapa fluido y cotidiano de conflictos, así como un registro de potenciales amenazas a la relación de gobierno, lanzando señales de advertencia al sistema político respecto a las anomalías ("focos amarillos"), a fin de mantener la gobernabilidad del régimen en niveles de normalidad.

b) Hacia la derecha del continuo, la acción mediática puede incidir en la visibilización (cuando no en la amplificación/ activación) del déficit de gobernabilidad, reforzando así su expresión manifiesta y acumulativa en un escenario de descontrol, lo cual podría propiciar el tránsito hacia una situación de crisis donde el elevado nivel de conflictos ponga en riesgo la estabilidad del régimen político, el mantenimiento de las autoridades de gobierno y la ejecución de las directrices políticas. Aquí cabe pensar en una función de detonación, en sentido de que los medios se desenvolverían como una especie de reflectores cotidianos de la brecha entre demandas sociales fragmentadas y respuestas gubernamentales insatisfactorias, dando cuenta de la proliferación de anomalías ("focos rojos") que pondrían en riesgo - crisis - la relación de gobierno.

Esta doble dirección en la que puede orientarse la acción mediática en relación a los grados de gobernabilidad (hacia una situación "normal" o hacia otra de crisis) 4 , así como la doble función que desarrollan los medios en situaciones políticas específicas (de alerta y de detonación), serán percibidas como favorables o nocivas - para la gobernabilidad - dependiendo de un conjunto de variables. Es decir, difícilmente podrá sostenerse, todo el tiempo y para todas las coyunturas, una visión globalmente mediófila o mediófoba del complejo mediático ${ }^{5}$. Esta advertencia es importante porque la puesta en escena mediática de "focos amarillos y rojos" puede ser, a la vez, un útil artefacto de prevención para evitar problemas de gobernabilidad, o un temerario dispositi-

4 La idea de grados de gobernabilidad ha sido planteada por Camou (1995) para dar cuenta de un continuo de situaciones políticas.

5 Planteo la distinción analítica entre mediófilos y mediófobos para dar cuenta de dos percepciones distintas sobre los medios. Los primeros conciben a los medios como "democratizadores" por excelencia del poder. Los segundos anuncian la inminencia del poder de los medios ("mediocracia") y plantean escenarios catastrofistas acerca del futuro de la política y de la democracia. 
vo para la propagación del descontrol. El curso que se siga, en todo caso, depende menos de la bondad o maldad de los mass media que del nivel e intensidad de movilización de los actores sociales, la (re)acción de quien tiene a su cargo la función/responsabilidad de gobierno, la vinculación entre gobernantes y gobernados, el grado de institucionalización de los actores estratégicos involucrados y la fortaleza/debilidad de eventuales o arraigados factores antisistémicos.

\section{Lo gobernable tematizado}

Planteo asumir un problema-guía: ¿cómo se manifiesta, en la agenda mediática, la in / gobernabilidad? En ese camino es posible distinguir tres espacios de influencia de la comunicación política:

a) La expresión de las demandas y reivindicaciones del polo gobernado, y su procesamiento como temas y opiniones dirigidos al sistema político.

b) La expresión de las respuestas y decisiones vinculantes del polo gobernante, y su relación con las reglas de atención y decisión respecto a la sociedad.

c) La intermediación entre demandas sociales y respuesta gubernamental, ya sea en función de canalización o como filtro.

En el primer caso nos referimos a la manera en que la agenda mediática traduce informativamente - o se apropia de - la agenda de los públicos (nexo medios/ ciudadanos); en el segundo, al modo en que los medios exponen informativamente - o buscan incidir en - la agenda político-institucional (nexo medios/políticos); y en el tercero, a la forma en que la mediatización se desempeña como soporte/instrumento del (des)encuentro entre ambos procesos y cómo incide en ese vínculo (ciudadanos/políticos) en el marco de la relación de gobierno en un régimen político.

Establecido así el mapa general del problema, podemos ya abordar cada uno de los tres espacios. Empecemos explorando de qué modo influye la función de agenda mediática - en el supuesto de que determina sobre qué pensar (temas), qué pensar (clima de opinión) y cómo pensar (estrategias de interpretación) - en la expresión de la demanda social ${ }^{6}$. Lo primero es que los mass media (en especial la televisión) constituyen la fuente de información política más importante para los actores sociales; es decir, son su proveedor principal de noticias respecto a la política y a lo que hace o deja de hacer el gobierno. En ese sentido, la acción mediática, multiplicadora de expecta-

6 Según los supuestos de la agenda setting, los medios establecen el orden del día de los asuntos públicos bajo un criterio selectivo que incluye unos temas a la vez que excluye otros; ordenan tales temas, a modo de lista jerarquizada, otorgándoles un rango de importancia; y, por último, los difunden con determinado formato, atributos y enfoque interpretativo. Al respecto véanse especialmente los trabajos de Semetko (1995), Bregman (1998) y Charrón (1998). 


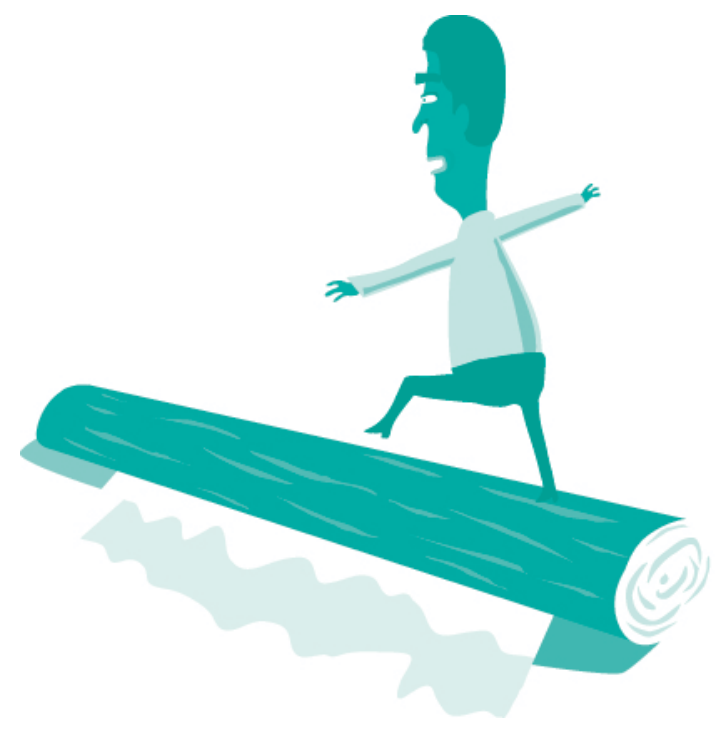

tivas, establece de algún modo el marco temático e interpretativo de referencia a partir del cual el polo gobernado planteará sus demandas al polo gobernante. Otorga pues, a los actores sociales, instrumentos para orientar su relación con el sistema político, facilitando sus fines de movilización y participación.

En una aproximación más específica podemos sostener que los medios de comunicación contribuyen tanto al procesamiento y la captación de la demanda social, como a su exposición en calidad de asunto de interés público. Ello supone la existencia de un criterio de relevancia no sólo para elegir/priorizar unos temas en desmedro de otros, sino también para fomentar la presencia mediática de determinados actores y grupos de interés - aquellos con mayor capacidad de movilización y, por ello, más dispuestos a presionar al sistema político y a los propios medios -, en menoscabo de otros ciudadanos poco organizados y cuyas reivindicaciones, en general, carecen de impacto informativo. Resulta pertinente distinguir, en consecuencia, entre las demandas que se ponen en la palestra pública (son visibilizadas) por iniciativa de los operadores mediáticos; las que provienen de actores individuales o grupales y que, dependiendo de su importancia y fortaleza, son articuladas (publicitadas) por los medios como hechos noticiosos; y las demandas que, respaldadas en la "opinión movilizada" de actores/movimientos sociales, son difundidas por los mass media como parte de su agenda, reciben especial seguimiento informativo e incluso se convierten en privilegiado asunto de opinión. Será evidente que mientras más respaldo social adquiera la demanda, y mayor capacidad tenga de poner en cuestión la conservación/adaptabilidad del sistema, menos dependerá de los medios para existir y más posibilidades tendrá, por cuenta propia, de activar la atención - cuando no la decisión - del polo gobernante.

Esto último nos conduce a un punto central para el debate: que si bien la mediatización es un referente del que difícilmente se puede prescindir en la comunicación política, no todas las reivindicaciones sociales y desafíos políticos necesariamente tienen que "pasar" por los medios para demandar respuesta gubernamental. Pero eso no constituye lo más relevante. El asunto crítico radica en su contracara. Es decir, que no to- 
das las demandas que se dirigen al sistema político provienen como tales de los actores sociales, lo cual plantea la posibilidad de que los mass media presenten como reivindicaciones del público sus propias peticiones e intereses, tarea en la cual cuentan a su favor, iy de qué modo!, con el "expediente legitimador” de los sondeos.

\section{Seis modos de acción}

Pero avancemos en una base de clasificación de los modos en que la acción mediática interviene en la expresión de la demanda social. Para el efecto propongo identificar seis ejercicios estratégicos ${ }^{7}$ :

- Visibilización/ampliación: la acción de los medios pone en escena (difunde masivamente) los temas de los actores sociales y, por ese camino, les otorga publicidad e induce su reconocimiento en el sistema político, lo cual no necesariamente implica que éste active sus compuertas de atención y, menos, convierta tales asuntos en objeto de políticas públicas.

- Ocultamiento/disminución: la agenda mediática puede otorgar un status marginal a determinados temas de la agenda pública que carecen de potencial de movilización o de difundibilidad noticiosa (especialmente en la televisión); e incluso llegan a provocar un "efecto sustitución" al procesar demandas que, por su sola expresión mediática, ya no se dirigen como tales al sistema político.

- Sostenimiento/intensificación: los medios pueden prolongar la presencia de un tema en la agenda informativa, reciclándolo permanentemente (como tema nuevo, a veces "artificial"), por más que su planteamiento como demanda social haya perdido relevancia o pertinencia en un momento determinado; y también pueden replantear temas, ya atendidos en el sistema político, con renovada amplitud e intensidad.

- Distorsión/desviación: los medios pueden deformar, en su tratamiento informativo, las demandas planteadas por los actores sociales, lo cual tiende a alterar tanto su sentido cuanto su alcance; y en ese mismo camino podrían también desfigurar las reivindicaciones sociales, ya sea por efecto de su simplificación o por su expresión en clave de espectáculo-conflicto.

- Jerarquización/fragmentación: los medios otorgan un orden de importancia a los temas en su agenda, lo cual no necesariamente coincide con la jerarquización temática realizada por los actores sociales; pero además de organizar las demandas sociales de acuerdo a un criterio de relevancia definido por los propios medios, tienden a fragmentar las demandas, presentándolas como unidades sin contexto $\mathrm{y}$, a veces, carentes de referente colectivo (personalizadas y sin Sujeto).

7 Estas funciones son una ampliación de las tres estrategias reductivas de la demanda planteadas por Offe (1981) y expuestas en el anterior apartado: desviar, frenar o disminuir; las cuales hemos complementado con sus correspondientes estrategias, opuestas, de refuerzo: concentrar, promover e incrementar. 
- Creación/reconstrucción: la agenda mediática no sólo incorpora y jerarquiza los temas planteados por los actores, sino también puede crear nuevas demandas o reponer (reconstruir) viejos asuntos otorgándoles algún componente de actualidad noticiosa o pertinencia pública; asimismo, los medios, en su alianza con los sondeos de opinión, pueden introducir temas e interpretaciones respecto a una nutrida variedad de asuntos.

Así las cosas, para evitar equívocos y no otorgarle a la construcción de agenda más poder e influencia de la que realmente tiene, conviene insistir en que, primero, los medios de comunicación no sustituyen (ni pueden ignorar todo el tiempo) a los sujetos sociales y sus reivindicaciones; segundo, que los actores sociales despliegan permanentemente, ante la mediatización, estrategias no sólo de visibilización de sus demandas, sino también de participación en la construcción de la agenda informativa - es decir, puede establecerse una suerte de relación instrumental (conexión/desconexión) de los gobernados respecto a los medios -; y, tercero, que el grado de incidencia de la agenda mediática en el procesamiento y expresión de las demandas sociales / desafíos políticos está en relación directa con variables tales como el número de reivindicaciones, su amplitud e intensidad, la fuerza de sus portadores, el nivel de organización y movilización de los actores sociales y el tipo de relación que establezcan, en coyunturas específicas, con el sistema político. En ese sentido, si bien es evidente que cada vez con mayor frecuencia la expresión de demandas sociales busca realizarse de cara a los mass media para adquirir, por esa vía, mayor presencia en el espacio público; también es cierto que, más allá del impacto inmediato (espectáculo/ escándalo noticioso) de la mediatización, tales demandas pueden pasar perfectamente desapercibidas, y languidecer, ante las instancias de decisión del sistema político. Es decir, los medios tendrán amplia influencia en tematizar las demandas, pero no garantizan nada en cuanto a su tratamiento como problema socialmente considerado ni, menos, como objeto de política pública. Hasta aquí el primer espacio de influencia.

\section{El otro polo, el gobernante}

Segundo escenario. ¿Cómo influyen los mass media, en su función de construcción de agenda informativa, en el procesamiento/ expresión de la respuesta en el polo gobernante? De inicio son necesarias dos premisas. La primera en sentido de que, como el sistema político no puede interesarse por demasiados temas ni, menos, darles tratamiento regulatorio (capacidad que varía dependiendo de la fortaleza e institucionalización del gobierno/ aparato estatal), la acción mediática será decisiva para activar tanto los mecanismos de atención cuanto, en menor medida, los dispositivos de decisión del sistema respecto a determinados temas y opiniones "del gran público". La segunda premisa, a su vez, en tanto que, como el ejecutivo/aparato estatal tiene la obligación/derecho de informar a la sociedad sobre el curso de la función y responsabilidad de gobierno, los mass media desempeñan un papel central en la canalización, hacia los 
actores sociales, de la información política del polo gobernante; pero, al mismo tiempo, la agenda mediática es clave para hacer llegar, al centro del sistema, las reacciones/ consecuencias del polo gobernado, tanto ante decisiones anteriormente tomadas como respecto a nuevas demandas resultantes de ese proceso.

Así, la construcción de la agenda informativa puede influir, respecto al sistema político, en tres niveles. El primero es el procesamiento de la decisión política en el marco institucional del Poder Ejecutivo, lo que tiene que ver con el conjunto de mensajes que circulan en el interior del sistema y con la vocería informativa por parte de quienes ejercen la función/responsabilidad de gobierno. El segundo nivel se ubica en el conjunto de la estructura estatal, y se refiere específicamente al modo en que la agenda mediática incide en las relaciones entre los poderes del Estado, con especial atención a los flujos comunicativos entre el Ejecutivo y el Legislativo para el procesamiento de demandas sociales y desafios políticos (en particular entre la cabeza/ entorno del gobierno y - si fuese el caso - la mayoría oficialista en el Parlamento, más aún si ésta es producto de una coalición política que involucraría también a los partidos - incluidos los de oposición - en el proceso comunicacional). Y el tercer nivel, respecto al actor que tiene a su cargo el ejercicio de la gobernabilidad, se refiere a la llamada "esfera social" del Estado, la cual indica la relación del sistema político con su entorno, y la forma en que los medios podrían influir en el nexo entre la agenda político-institucional y los inputs que recibe el sistema.

Pero quizás la incidencia más destacada de los medios masivos en el polo gobernante - en el horizonte de la in/gobernabilidad - sea no tanto lo que buena o distorsionadamente incluyan como tema en la agenda informativa (lo que dicen), sino más bien lo que excluyen (y por tanto callan) de la consideración pública. Así, mientras respecto a los actores sociales la acción mediática enfatiza la visibilización y publicidad de reivindicaciones específicas, en relación al sistema político será fundamental la función periodística de revelar/transparentar la acción del Ejecutivo / aparato estatal, así como sus "secretos" y consecuencias. Ello, desde la óptica del sistema político en sus fines de conservación y adaptación, es importante a la hora de procesar tanto las respuestas gubernamentales al conjunto de demandas de la sociedad, como las políticas para el automantenimiento del régimen político.

Esto último nos conduce a la paradoja de que, cada vez con mayor frecuencia, la respuesta/ decisión gubernamental estaría orientada no tanto a resolver la demanda social, sino a calibrar la reacción de los medios; esto es, buscar una versión informativa conveniente o, en su caso, atenuar una desfavorable. Paradoja, decimos, porque si en efecto la acción mediática ha convertido la función/responsabilidad de gobierno en una actividad más pública y visible, también está condicionando a los gobiernos en una especie de obsesión por su imagen mediática. Para equilibrar las cosas, empero, en mirada mediófila se podría decir que la presión de los medios no necesariamente induce o desfigura la respuesta gubernamental; más bien, la hace posible. 


\section{Elogio de la mediatización}

A reserva del complejo debate sobre si los medios de comunicación, respecto al ejercicio de gobierno y su capacidad de definir decisiones vinculantes, son predominantemente facilitadores o, más bien, obstructores, quizás sea de mayor utilidad analítica insistir en la doble función de la agenda mediática como "vocera" de la demanda social, por una parte, y "traductora" de la respuesta gubernamental/ estatal, por otra. Esto es, como espacio en el que se construyen temas a la vez que se activan mecanismos de atención. Y aquí pasamos al tercer espacio de influencia de la acción de los mass media: la intermediación entre demanda y respuesta en el escenario de la in/gobernabilidad.

¿Cómo interviene la agenda de los medios en la interacción entre los polos gobernante y gobernado? El supuesto es que si la problemática de lo gobernable del régimen político se ubica en el nexo entre demanda social (más o menos desmedida) y capacidad gubernamental (más o menos sólida), en la perspectiva de la gobernabilidad mediática la dinámica tiende a trasladarse hacia otros dos espacios: la expresión de la demanda social en la agenda mediática, por un lado; y la inclinación de la decisión política hacia la acción informativa en los medios, por otro. Es decir, más que canalizador/filtro entre unos y otros, el complejo mediático parece constituirse en uno de sus principales puntos de (des)encuentro. Que ello derive en diálogo para la conciliación de intereses, o se traduzca en columna de conflictividad para la relación de gobierno, dependerá de cada situación específica, de cada medio concreto y del tipo de intercambios establecidos entre los actores involucrados.

Lo relevante es que la pregunta acerca de cuán mediáticamente "agendable" es la in/gobernabilidad dependerá no sólo de la influencia de los medios de comunicación, sino fundamentalmente de cuán amplia e intensa sea la demanda, cuán eficaz y oportuna sea la respuesta, y qué tan expedita e institucionalizada sea la relación (en el marco del principio de representación política y los canales de participación ciudadana existentes) entre el sistema político y la sociedad.

\section{Una mirada a los actores}

No quiero concluir esta aproximación a la gobernabilidad mediática sin hacer breve referencia a un tema central en la comunicación política: la influencia, sobre la in/gobernabilidad, de las diferentes tácticas y estrategias adoptadas por los actores políticos y mediáticos. Que predominen relaciones de rivalidad (competencia), de intercambio (cooperación) o de complicidad (colusión) ante determinadas situaciones políticas incidirá tanto en la presentación noticiosa de las directrices políticas y sus resultados, cuanto en la orientación de apoyo o rechazo a alguna autoridad pública, al gobierno en su conjunto o al régimen político. Si bien, en general, se afirma que las relaciones más fre- 
cuentes son las de conflicto, no son menos importantes los nexos de interdependencia y hasta de alianza entre políticos y periodistas (gobierno y medios), lo que tiene que ver con los límites (auto) impuestos en la comunicación política ${ }^{8}$.

Así abonado el terreno podemos plantear algunas señales específicas de síntesis respecto a la incidencia de los mass media, en el ámbito de la comunicación política, sobre la in/gobernabilidad del régimen político.

a) Los medios de comunicación, entendidos no sólo como difusores/escenario sino especialmente como protagonistas (de la democracia y de la gobernabilidad), no son $e l$ actor omnipotente que podría pensarse que es, sino un actor ciertamente estratégico, pero en interacción con otros grupos igualmente importantes en términos de poder y control de recursos políticos. Esto implica que la acción mediática sólo puede entenderse como parte de ese entramado de relaciones entre actores en el marco de reglas que las rigen.

b) La gobernabilidad no es un estadio estático y absoluto sobre el cual puede indagarse la influencia de los medios masivos cual si éstos fuesen un factor externo, sino una construcción dinámica siempre relativa y relacional que se desarrolla en el propio proceso de comunicación política en el horizonte de la función/responsabilidad de gobierno. Esto plantea un cambio, al menos, en la formulación del problema en sentido de que ya no se trata de examinar la incidencia de la acción mediática sobre la gobernabilidad, sino la capacidad de acción de los medios en las relaciones de poder - de las cuales forma parte - que generan (in)gobernabilidad.

c) Lo gobernable del régimen político no se limita a la interacción, más o menos compleja y conflictiva, entre demanda social y respuesta gubernamental, sino que implica algo así como una negociación permanente, muy o poco institucionalizada, de las fórmulas mínimas que permitirán el curso estable de la relación de gobierno. En ese sentido, además de la amplia influencia de los mass media sobre la expresión de los desafíos políticos por parte de la sociedad y de las decisiones vinculantes desde el gobierno/aparato estatal - así como en las dimensiones de legitimidad y eficacia de la gobernabilidad -, será decisiva la consideración de los medios como actores capaces de aceptar o no las fórmulas predominantes, así como de cambiarlas.

d) Los medios de comunicación, en tanto actores protagónicos de la gobernabilidad, no se restringen al uso de información e ideas, sino que procuran controlar más recursos políticos desplazando a (en pugna con) otros actores estratégicos. En ese sentido será fundamental ya no la aceptación y cumplimiento de las reglas, sino la capacidad y posibilidades de la acción mediática de asumir las otras tácticas (acep-

8 Para ampliar la discusión sobre la comunicación política y sus efectos, sugerimos la revisión de los trabajos de Bretón (1998), Gosselin (1998), Muñoz-Alonso y Rospir (1995), Muñoz-Alonso (1999) y Wolton (1998). 
tación sin cumplimiento, rechazo sin ruptura, quiebra de la fórmula) que pueden conducir a la ingobernabilidad 9 .

Es sobre la base de esta última consideración que concluyo con el planteamiento de una pregunta clave pero de difícil respuesta: ¿hasta dónde están dispuestos a llegar, o son capaces de hacerlo, los medios de comunicación en el horizonte de la gobernabilidad del régimen político? Queda como tema para el análisis comparado y para el debate.

\section{Bibliografía}

BREGMAN, Dorine. La función de agenda: una problemática en transformación. In: FERRY; WOLTON et al. El nuevo espacio público. Barcelona: Gedisa editorial, 1998. p. 210-223.

BRETON, Philippe. Medios, mediación, democracia. In: GAUTHIER; GOSSELIN; MOUCHON (comp.). Comunicación y política. Barcelona: Gedisa editorial, 1998. p. 356-371. (1 $1^{\text {a }}$ edición en francés, 1995).

CAMOU, Antonio. Gobernabilidad y democracia. Cuadernos de Divulgación de la Cultura Democrática, México D.F., n. 6, p. 65, 1995.

CHARRON, Jean. Los medios y las fuentes. Los límites del modelo de agenda-setting. In: GAUTHIER; GOSSELIN; MOUCHON (comp.). Comunicación y política. Barcelona: Gedisa editorial, 1998. p. 72-94. (1ª edición en francés, 1995).

COMISION TRILATERAL: La gobernabilidad de la democracia. Cuadernos semestrales, México D.F., 10 trimestre, n. 2-3, p. 377-397, 1977. (Informe del Grupo Trilateral. Redactores: Michael Crozier, Samuel Huntington y Joji Watanuki).

COPPEDGE, Michael. Instituciones y gobernabilidad democrática en América Latina. Síntesis - Revista de Ciencias Sociales Iberoamericanas, México D.F., n. 22, p. 61-88, 1994.

EXENI R., José Luis. Mediamorfosis: comunicación política e (in)gobernabilidad en democracia. La Paz: PluralEdiciones Fado, 2005. p. 278.

GAUTHIER, Pilles; GOSSELIN, André; MOUCHON, Jean (compiladores). Comunicación y política. Barcelona: Gedisa editorial, 1998. p. 413. (1ª edición en francés, 1995).

GOSSELIN, André. La comunicación política. In: GAUTHIER; GOSSELIN; MOUCHON (compiladores). Comunicación y política. Barcelona: Gedisa editorial, 1998. p. 9-28. (1ª edición en francés, 1995).

HUNTINGTON, Samuel. El orden político en las sociedades de cambio. Barcelona: Paidós, 1990. (1ª edición, 1968)

9 Estas diferentes tácticas han sido bien plantadas por Coppedge (1994), de quien retomamos el horizonte analítico en esta parte del artículo. 
GOBERNABILIDAD MEDIÁTICA - MASS MEDIA Y GRADO DE GOBIERNO: DIFÍCIL (DES)ENCUENTRO • JOSÉ LUIS EXENI

LUHMANN, Niklas. Opinión pública. In: Stato di diritto e sistema sociale. Napoli: Guida, 1978. p. 214 (traducción al español de Cecilia Gayet, Flacso México).

MANIN, Bernard. Los principios del gobierno representativo. Madrid: Alianza Editorial, 1998. p. 300.

MUÑOZ-ALONSO, Alejandro; ROSPIR, Juan Ignacio (editores). Comunicación política. Madrid: Editorial Universitas, 1995. p. 387.

(editores). Democracia mediática y campañas electorales. Barcelona: Ariel, 1999. p. 222.

OFFE, Claus. Ingobernabilidad. El renacimiento de las teorías conservadoras. Revista Mexicana de Sociología México D.F., Instituto de Investigaciones Sociales, ano XLIII, vol. XLIII, número extraordinário, E/81, p. 18471866, 1981.

SEMETKO, Holli A. Investigación sobre tendencias de la agenda-setting en los noventa. In: MUÑOZ-ALONSO; ROSPIR (editores). Comunicación Política. Madrid: Editorial Universitas, 1995. p. 221-241.

SWANSON, David L. El campo de la comunicación política: la democracia centrada en los medios. In: MUÑOZALONSO; ROSPIR (editores). Comunicación Política. Madrid: Universitas, 1995. p. 3-24.

WOLTON, Dominique. La comunicación política: construcción de un modelo. In: FERRY; WOLTON et al. El nuevo espacio público. Barcelona: Gedisa editorial, 1998. p. 28-46. (1ª edición en francés, 1989).

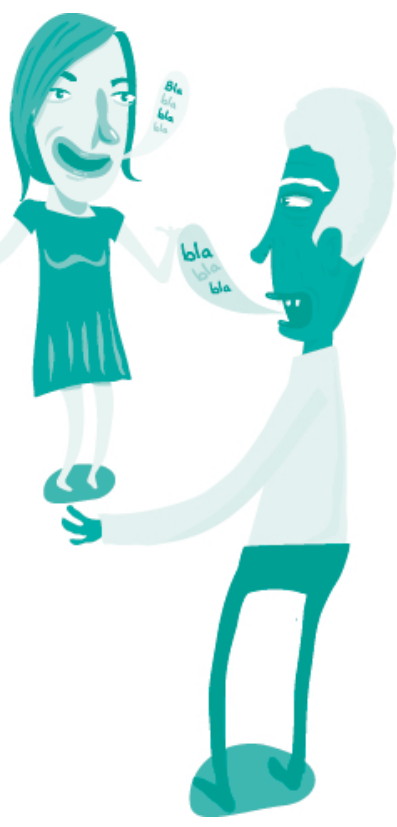

